\title{
La devaluación de los prioratos de la orden de San Juan en Castilla y León a mediados del siglo XVII
}

\author{
Josefina CASTiLla Soto*
}

A lo largo del siglo XVII tuvo lugar una importante crisis en la economía castellana, que los distintos especialistas en el tema se han ocupado de destacar, señalando sus motivaciones y cuantificando sus efectos ". Naturalmente los Prioratos de la Orden de San Juan en Castilla y León no escaparon a estas circunstancias, aunque mostraron unas connotaciones muy particulares que trataremos ahora de exponer a grandes rasgos.

Es importante tener en cuenta a la hora de establecer el interés del tema en cuestión, que a comienzos de la centuria los Prioratos de la Orden de San Juan en Castilla y León estaban valorados en unos 100.000 ducados, mientras que a mediados del siglo XVII esa cifra se había reducido a unos 60.000 ducados $^{2}$. A partir de aquí se abren los grandes interrogantes sobre las verdaderas causas que llevaron a los Prioratos a una devaluación tan notoria.

UNED. Madrid.

Sólo a modo de orientación sobre el tema, podemos recordar varios títulos, algunos de ellos ya clásicos: ANEs, G., Las crisis agrarias en la España Moderna. Madrid 1970. Congreso de Historia Rural. Siglos Xv al xix. Actas del Coloquio celebrado en Madrid, Segovia y Toledo, 13.16 de octubre de 1981. Madrid 1984. LOPEZ SALAZAR, J., Estructuras agrarias y sociedad rural en La Mancha (siglos XVI-XVII). Ciudad Real 1986. LLOPIS AGELAN, E., "El agro castellano en el siglo xvII: ¿Depresión o "reajustes y readaptaciones"?", Revista de Historia Económica, IV/1, 1986, págs. 11-37. WEISER, M. R., "The Agrarian Depression in Seventeenth-Century Spain», The Journal of Economic History, 42, 1984, págs. 141-168.

2 AGS, Estado, leg. 2964. Conviene señalar para situarnos geográficamente en el tema, que los Prioratos se extendían por las siguientes villas y lugares: Consuegra, Turleque, Madridejos, Tembleque, Villacañas, Herencia, Camuñas, Urda, Arenas, Villaharta, Alcázar, Argamasilla, Villafranca, Quero, Manzanares, Campo de Criptana, Puebla de don Fabrique, Mora, Yébenes, Villarrubia, Fuente del Fresno y Daimiel. Estos lugares aparecen así señalados en AGS, C y SR, leg. 237. 
En el ánimo de los miembros de la Orden pesaba, en gran medida, la ausencia de un gobierno fuerte al frente de los mismos ${ }^{3}$. Hay que recordar que siendo aún muy joven y tras una serie de polémicas vicisitudes, había accedido al Priorazgo de la Orden de San Juan en Castilla y León, don Juan de Austria, hermanastro de Carlos II.

Concretamente en 1624 y tras el fallecimiento del Príncipe Filiberto, le sucedió en el gobierno de los Prioratos el Bailío de Lora, don Diego Brochero, quien tan sólo permaneció cuatro meses en el cargo. Muerto éste, el Rey, en lugar de utilizar su facultad de elegir la persona que consideraba idónea para el gobierno de los Prioratos, en virtud de una Bula papal que le había sido otorgada el 14 de junio de $1625^{4}$, requirió y obtuvo de Su Santidad otra Bula, de 31 de enero de 1626, en la que se le concedía el privilegio de poder nombrar para esa vacante al fraile Caballero de la Religión a quien corespondiera por derecho de ancianidad reservando para otra persona, expresamente nombrada por el Rey, los frutos de la dignidad prioral, aunque descontando los gastos y derechos correspondientes al tesoro común de la Religión y 6000 ducados anuales más la jurisdicción y vasallaje para el Caballero Prior, mientras durase la reserva de los frutos.

Así el 5 de noviembre de 1626, Felipe IV nombró al Señor Infante don Carlos usufructuario y administrador de las rentas priorales, mientras que el cargo de Gran Prior recaía en don Bernardino de Zúñiga, Bailío del Sepulcro de Toro «a quien declaró la religión, tocaba serlo».

El 9 de octubre de 1632, el Papa Urbano VIII otorgó de nuevo una Bula al monarca católico por la que se le concedía el privilegio de poder nombrar a una persona de su real sangre para ocupar el cargo de Gran Prior de Castilla y León si se producía el fallecimiento de don Bernardino de Zúñiga ${ }^{5}$. A este efecto, el 14 de enero de 1634 la Religión de San Juan extendió un documento encabezado por Fray Antonio de Paula,

\footnotetext{
3 «... porque ay muchos dueños para desfrutalle y ninguno para gobernalle y el berdadero Gran Prior es el Contador Mayor..." (AGS, Estado, leg. 2963).

4 AGS, Estado, leg. 2972.

«... conçediendo su santidad, desde luego, a la tal persona asi nombrada (para quando lo estubiese) que pudiese reçivir el ávito Regular y la gran cruz y haçer a su tiempo la profesión espresa y Regular, y que después del nombramiento puciese tomar la posesión del priorato en vacando y goçar los frutos pagando todos ios derechos que se deviesen a la Religión, y que si al tiempo del nombramiento no tubiese el nombrado la hedad competente, pudiese Su Magestad nombrar un cavallero profeso de la Religión que le pareçiese para que en nombre de la persona que Su Magestad nombrase, y hasta que tubiese hedad sufiçiente, exerciese y administrase la jurisdicción tocante al dicho priorato» (AGS, Estado, leg. 2972. Bula de Urbano VIII de 9 de octubre de 1632).
} 
Maestre de la Casa del Hospital de San Juan de Jerusalén y de la Orden Militar del Santo Sepulcro, en el que se ratificaba y aceptaba la Bula otorgada el 9 de octubre de 1632 en favor de Felipe IV ${ }^{6}$. Así pues, éste podría nombrar a alguien de su sangre de modo que el Gran Prior designado tendría derecho a retener la posesión del Priorato con todos sus bienes, jurisdicciones y frutos a excepción de los derechos debidos al tesoro común de la Orden, los impuestos establecidos y la pensión Maestral de 500 ducados sobre los frutos priorales, debida al Maestre.

En virtud de esta concesión ratificada además por los sanjuanistas el 2 de marzo de 1626, Felipe IV decidió el nombramiento, en secreto por no alcanzar la edad suficiente, de don Juan como Gran Prior de San Juan en Castilla y León ? Éste se hizo efectivo en 1642 en San Lorenzo de El Escorial, si bien don Juan no pudo profesar con plenos derechos hasta 1645 con motivo de cumplirse su decimosexto aniversario. El Papa ratificó, mediante un Breve, la recepción de la dignidad prioral por parte de don Juan ${ }^{8}$.

Sin embargo, según los estatutos eclesiásticos, todo prior o bailío, para poder ejercer su gobierno plenamente, debía cumplir dos condiciones: tener más de 31 años y 15 de hábito. Obviamente en don Juan no concurrían tales requisitos por lo que no podía gobernar los Prioratos sin la asistencia de un teniente, dada además la complicación que suponía la administración de la dignidad prioral ${ }^{9}$.

El Papa otorgó dørecho a Felipe IV para que nombrara teniente de don Juan a la persona que considerara más idónea para el desempeño de dicha función durante la minoría del nuevo Gran Prior.

El monarca resolvió tres provisiones en torno a los Prioratos. En primer lugar, se nombraba a don Juan de España, Contador Mayor del Priorato.

AGS, Estado, leg. 2966.

AGS, Estado, leg. 2972. La edad para profesar como Gran Prior era la de dieciseis años y don Juan entonces, no contaba sino con siete.

8 AGS, Estado, leg. 3267, fol. 167. Breve expedido por Roma el 13 de junio de 1643.

9 AGS, Estado, leg. 2968. La administración y gobierno de los Prioratos entrañaba múltiples deberes:

1) Presentación de beneficios curados y simples.

2) Nombramiento de Vicarios para administrar la jurisdicción eclesiástica.

3) Escuchar pleitos eclesiásticos y seglares, civiles y criminales.

4) Sentenciar dichos pleitos.

5) Acudir al gobierno político de las villas que constituían la dignidad prioral.

6) Gobierno y nombramiento de Prioras y Abadesas de cinco converitos de monjas que estaban bajo la responsabilidad del Gran Prior.

7) Nombramiento de Visitadores Generales para asuntos espirituales y temporales, para los bailiajes y encomiendas de Castilla. 
En segundo lugar se ordenaba a Francisco de Iriarte su ida a los Prioratos en calidad de secretario para realizar cuentas, ajustar el valor de las rentas y tomar las resoluciones más convenientes para su más correcta administración. Por último, se hacía merced al licenciado Garcés de Acosta, del puesto de Gobernador de los Prioratos en ausencia de don Juan ${ }^{10}$.

De este modo se iniciaba la andadura del hijo de Felipe IV como Gran Prior de San Juan en los Reinos de Castilla y León. La tarea, en principio, no se presentaba nada fácil dada la juventud del personaje. Por otra parte, hubo un cierto desencanto entre los miembros de la Orden, los cuales habian confiado en la recepción de grandes mercedes prometidas por Felipe IV con motivo de la creación de la casa de su Alteza Serenísima. Sin embargo, a ella se incorporaron escasos Caballeros de hábito ${ }^{11}$.

A comienzos de 1645, casi coincidiendo con la toma de posesión de los Prioratos con plenos derechos por parte de don Juan, el Rey dio unas precisas instrucciones sobre el estilo y gobierno que debían observarse en la casa de su hijo. En este sentido, resultaba primordial la existencia en su sede de Consuegra, de un arca con tres llaves para el tesorero, contador y grefier, respectivamente, conteniendo las rentas de los Prioratos de San Juan, las demás rentas otorgadas a don Juan y las cantidades destinadas particularmente por el Rey para el gasto y mantenimiento de la casa ${ }^{12}$. Ésta no constituyó un elemento estable e inamovible, antes al contrario, fue muy variable al igual que los sucesivos destinos que don Juan se vio obligado a atender ${ }^{13}$. Por regla general, cuando éste se trasladaba para el desempeño de su cargo, parte de los criados permanecía en los Prioratos, moviéndose sólo un sector de la casa.

Precisamente la falta de un gobierno fuerte y estable al frente de los Prioratos fue frecuentemente denunciada por distintos miembros de la Orden, los cuales se mostraban partidarios de que su gobierno hubiera estado mejor en manos de una persona secular y no de un Caballero de hábito, que además era hijo del Rey ${ }^{14}$.

\section{AGS, Estado, leg. 2972}

AGS, Estado, leg. 2963.

AGS, Estado, leg. 2964. Instrucción de 16 de febrero de 1645, dada por Felipe IV.

Efectivamente don Juan se vio obligado a compaginar su cargo de Gran Prior con múltiples ocupaciones de índole militar y política a lo largo de su vida. Véase Castilla Soto, J., Don Juan José de Austria (hijo bastardo de Felipe IV): su labor política y militar. Madrid 1992.

14 AGS, Estado, leg. 2972. D. Lorenzo de Ugen, contador de los Prioratos, no dudaba en señalar como uno de los motivos de la devaluación de la hacienda prioral, el hecho de que estuvieran en manos del gobierno de don Juan. Esto lo hacía en un informe de 2 de enero de 1645 . 
Aparte de estas consideraciones también se esgrimian, a la hora de justificar la devaluación, importantes diferencias entre la administración Ilevada a cabo en épocas pasadas y la verificada a mediados del siglo XVII. Tradicionalmente se había venido prestando un tercio de los diezmos a los labradores en la época de la siembra, cantidad que generalmente devolvían en agosto, bien en dinero o bien es especie ${ }^{15}$. Las consecuencias de dicha tradición, en opinión de muchos miembros de los Prioratos, detractores de los encargados de su administración, resultaban altamente beneficiosas para las rentas priorales ya que al sembrar a tiempo y en cantidad gracias a las tazmías, las cosechas solían ser más abundantes y con ellas los diezmos a pagar. Así pues, señores y labradores salían beneficiados. Por otro lado, suponía una ampliación de las tierras productivas ya que al socorrer a los labradores con el dinero de los diezmos, disminuía la extensión de tierras baldías o en barbecho, logrando una mayor productividad.

Sin embargo, cuando don Juan de Austria se hizo cargo de los Prioratos, dicha costumbre se había perdido ya que, o no se acudía en ayuda de los labradores con el tercio de los diezmos, o bien se hacía a destiempo cuando había pasado ya la época de la siembra ${ }^{16}$.

Naturalmente llegando a este punto de la administración de la hacienda prioral, no faltaron las críticas hacia el contador de los Prioratos al que se acusaba de no rendir cuentas, entre otras causas porque tampoco se le solicitaban:

«Don Lorenzo de Ujen, contador que fue destos prioratos, se tomó más mano de la que le tocava por su officio, el qual dava bales a renteros y mayordomos no debiendo más que tener la quenta y razón de la administración de la hacienda de V.A..." ${ }^{17}$.

Incluso se prodigan las referencias a posibles fraudes por parte del contador y de aquellos ocupados en la gestión prioral:

«... el Contador entró en la Villa de Consuegra el año de 1655 vestido de Licenciado, con una maleta sin otros bienes y oy tiene coche, cavallo y muchas galas él y su muger, comprando cada día alajas y con un gasto de familia que con dos mil ducados, no se puede sustentar..." ${ }^{18}$.

AGS, Estado, leg. 2964.

${ }^{6}$ " $\ldots$ este inconbeniente se atribuye realmente a la negligencia de los administradores que no haçen las tazmías tan a tiempo como importa para los empréstitos..." (AGS, Estado, leg. 2964).

17 AGS, C y SR, leg. 182. Informe fechado en Consuegra el 6 de septiembre de 1660.

18 AGS, C y SR, leg. 182. Referencias recogidas en un documento fechado en agosto de 1660. 
Por otra parte, no podemos olvidar que la renta de los Prioratos basada en los frutos recogidos, estaba enormemente condicionada por las cosechas y los precios de los cereales. A lo largo de este período, las cosechas descendieron acusadamente debido a múltiples factores. En concreto la climatología ocasionó desastrosas cosechas a mediados de la centuria provocando un declive de las mismas, como puede observarse a través de esta relación, realizada por el contador de los Prioratos entre los años 1639 y $1644^{19}$.

\begin{tabular}{rrrr}
\hline & Trigo & Cebada & Centeno \\
\hline 1639 & 14.006 fanegas & 22.369 fanegas & 1.871 fanegas \\
1640 & 9.629 fanegas & 13.735 fanegas & 917 fanegas \\
1641 & 9.603 fanegas & 13.015 fanegas & 859 fanegas \\
1642 & 14.815 fanegas & 16.663 fanegas & 1.869 fanegas \\
1643 & 16.222 fanegas & 15.482 fanegas & 1.431 fanegas \\
1664 & 9.137 fanegas & 9.419 fanegas & 621 fanegas \\
\hline
\end{tabular}

Hay que tener en cuenta además, que cada año se pagaban en especie, en concepto de salarios o limosnas, 200 fanegas de trigo y 1600 fanegas de cebada. Incluso dos años después, en 1646, Castilla y Aragón se vieron afectadas por desastrosas cosechas que resultaron insuficientes para sostener las cargas y obligaciones del Priorato y sus criados. Por ello el Rey dio órdenes concretas de que no se aplicaran las cortas ganancias de la venta de los granos de los Prioratos, ni para el sustento de los ejércitos, ni para el pago de los gajes de los criados de la casa del Gran Prior, como se hacía normalmente ${ }^{20}$.

Este descenso en la recolección de granos acabó restando defensas a una población que también sucumbiría ante las epidemias de peste y tifus $^{21}$. Además de este descenso demográfico tan específico del siglo XVII, tuvo lugar un descenso cualitativo de la clase labradora sobre todo por motivos fiscales, en general aumento de los pechos y gravámenes ${ }^{22}$.

En medio de tan desoladora situación, el contador de los Prioratos alzó su voz para denunciar las enormes cantidades que, procedentes de las rentas de los Prioratos, se entregaban para el gasto, guardarropa,

19 AGS, Estado, leg. 2963. Relación del estado de las rentas de los Prioratos de San Juan desde 1639 a 1644, en relación con las cosechas.

20 AGS, Estado, leg. 2966.

21 NADAL, J., La población española (siglos XVl a xx). Barcelona 1984, pág. 37.

22 AGS, Estado, leg. 2964. 
mesadas... de la casa del Gran Prior ${ }^{23}$. Incluso llegó a ordenarse una investigación de estos gastos tan excesivos, por si se estaban produciendo desórdenes y fraudes entre los propios criados de don Juan.

En contrapartida, el 1 de mayo de 1645, el Priorato de Castilla debía al tesoro de la religión de San Juan más de 50.000 ducados en concepto de responsiones ${ }^{24}$. La mayor parte de dicha cantidad correspondía a las deudas creadas por el propio monarca durante el tiempo en que había gozado los frutos del Priorato, incluidos los primeros años de don Juan tras su nombramiento como Gran Prior ${ }^{25}$. Mediada la centuria, las deudas se habían hecho extensivas a varios empleados de la jurisdicción prioral.

Hasta aquí hemos tratado de configurar la situación que se vivía en los términos castellano-leoneses de la Orden de San Juan a mediados del seiscientos, enormemente mediatizada por la ausencia de un gobierno fuerte y estable, con importantes anomalías en su administración achacables en gran medida a sus propios gestores y en medio de una desastrosa situación común a toda la zona, y que acabó sumiendo la economía prioral en la máxima precariedad.

Sin embargo, la devaluación de los Prioratos hay que buscarla también, en ciertos problemas de índole jurisdiccional que contribuyeron igualmente a mermar sus rentas y que facilitaron, en ocasiones, abusos por parte de algunas autoridades, unas veces internas y otras ajenas a los propios Prioratos.

Estos problemas que hemos denominado de índole jurisdiccional, se pueden resumir en tres puntos:

$\left.1 .^{\circ}\right)$ Las «sernas».

2..$^{\circ}$ Las injerencias del poder real.

3. ${ }^{\circ}$ Los conflictos con el Arzobispo de Toledo.

Respecto al primer punto hay que destacar la existencia, en ciertos lugares del Priorato de Castilla, de «sernas», las cuales constituían un tipo

23 AGS, Estado, leg. 2964. Relación de los maravedíes, trigo, cebada y centeno que se han dado, gastado y pagado de las rentas de los Prioratos de San Juan, desde el mes de mayo de 1643, hasta el mes de mayo de 1645, para las mesadas de la casa de don Juan, portes, salarios de criados, etc. En esos dos años se han gastado por este concepto, veintisiete cuentos de maravedíes.

${ }^{24}$ AGS, Estado, leg. 2964.

25 Las responsiones debidas a la religión de San Juan se elevaban, cada año, a 8200 ducados de plata, más 500 ducados en concepto de "pensión» para el Gran Maestre. Además a partir de 1642, empezaron también a pagarse 2000 ducados de plata, destinados a las tábricas de Malta y otras necesidades de la religión. 
de heredad. Estas heredades se entregaban como gracia a los grandes Priores, los cuales gozaban el arrendamiento de todo lo sembrado, además de los diezmos correspondientes de todas las sernas.

El valor de todas las heredades ubicadas en el Priorato de Castilla era considerable ${ }^{26}$; de ahí la importancia que entraña destacar que toda esa riqueza quedaba apartada del fondo común de los Prioratos y pasaba a depender exclusivamente del Gran Prior de turno, el cual podía permitirse incluso, una mayor y más cualificada explotación de su heredades en detrimento del resto de los Prioratos.

Respecto a las injerencias del poder real, los administradores de los Prioratos, en distintas ocasiones elevaron sus quejas por la utilización por parte de Felipe IV del privilegio que otorgado en Cortes, le concedía la posibilidad de vender oficios en las villas y lugares de su Reino ${ }^{27}$.

Concretamente en los Prioratos los oficios se consideraban de orden eclesiástico y por tanto no enajenables, al margen de lo perjudicial que su venta resultaba para las villas ${ }^{28}$.

Otra muestra de la injerencia real en la evolución económica de los Prioratos, está en la orden dada por Felipe IV a través del Consejo de Castilla, según la cual los Prioratos debían abastecer a la Villa de Madrid con seis mil fanegas de trigo a la tasa. Ello entrañaba serios inconvenientes puesto que la cantidad de granos recolectada por los Prioratos quedaba muy menguada. Recordemos simplemente que en 1644, la cantidad de trigo recolectada había sido de nueve mil ciento treinta y siete fanegas. De ahí, había que restar además una parte destinada a los labradores para la siembra y otra para satisfacer en especie, cargas, salarios y limosnas.

Pero además de las continuas incursiones de Felipe IV en la evolución económica de los Prioratos, éstos se vieron inmersos desde los inicios del siglo XVII, en un prolongado pleito con el Arzobispo de Toledo, por la jurisdicción espiritual de los Prioritarios. A mediados de la centuria el pleito siguió adelante, impulsado fundamentalmente por el propio Arzobispo de Toledo ya que el Gran Prior se mantuvo firme en la creencia de que la jurisdicción de los Prioratos estaba exclusivamente en sus manos ${ }^{29}$. In-

25 AGS, Estado, leg. 2964.

27 Para una visión clara y rápida de la evolución de la venalidad de los oficios en Castilla, véase Domínguez OrTiz, A., "La venta de cargos y oficios públicos en Castilla y sus consecuencias económicas y sociales", en Instituciones y Sociedad en la España de los Austrias. Barcelona 1985, págs. 146-183

28 AGS, C y SR, leg. 231.

29 Ibidem. 
cluso la causa se recrudeció ante el intento por parte del Arzobispo, de introducir de nuevo la causa sobre los diezmos, lo que significaba su pretensión de diezmar también, los bienes poseídos por los religiosos de la Orden de San Juan, los cuales estaban exentos.

De este modo se fue prolongando en el tiempo un pleito cya base estaba en un auténtico diálogo de sordos acerca del presunto derecho jurisdiccional del Arzobispo de Toledo ${ }^{30}$.

Lo cierto es que la ausencia de un gobierno fuerte al frente de los Prioratos, los defectos en su administració, la desoladora situación agraria a merced de bruscos cambios climáticos y los problemas de índole jurisdiccional, sumieron los Prioratos de la Orden de San Juan en Castilla y León en una crisis traducida en una importante devaluación a lo largo del Seiscientos.

30 Algunos testigos fueron claros respectos a la situación de los Prioratos: «... son fuera de la dióçesis de Toledo... lo qual si se asentase nos daría el pleyto ganado...» (AGS, C y SR, leg. 231). Mientras tanto «... lo principal que el Arçobispo intentó aprobar, fue que los Prioratos estaban dentro de los límites de su Arçobispado...» (AGS, C y SR, leg. 182). 